\title{
TRADUCCIÓN INDEPENDIENTE DE LA ESTRUCTURA 5'cap DEL ARN GENÓMICO DEL VIRUS DENGUE
}

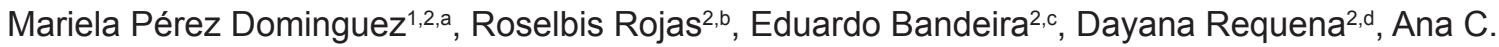 \\ Ferreras $^{2, \mathrm{e}}$, Juana L. Triana ${ }^{2, \mathrm{f}}$, Francisco Triana-Alonso ${ }^{2, \mathrm{~g},(\dagger)}$
}

\begin{abstract}
RESUMEN
Objetivos. Analizar la participación de la caperuza metil-guanosín-trifosfato ( $5^{\prime}$ cap) y de la región inicial del ARN genómico del virus dengue serotipo 2 (DENV-2) genotipo Americano en la traducción, utilizando un sistema libre de células obtenido de placenta humana. Materiales y métodos. Se preparó el plásmido recombinante pTZ18R-D2 conteniendo el ADN que codifica la 5'UTR y los primeros 201 nucleótidos de la cápside viral. Este plásmido se utilizó para transcribir el ARN correspondiente (ARN-D2), sin la 5'cap. El ARN-D2 fue traducido en un sistema constituido por la fracción posmitocondrial (S-30) de placenta humana y se evaluó la incorporación de $\left[{ }^{14} \mathrm{C}\right]$ aminoácidos en presencia del ARN-D2 y en su ausencia (control). Se diseñaron siete oligonucleótidos antisentido (OAs1-7) dirigidos contra secuencias de las estructuras SLA, SLB y cHP del ARN-D2 y se analizó el efecto de los mismos sobre la traducción ARN-D2. Resultados. El ARN-D2 produjo un incremento significativo $(p<0,001)$ en la incorporación de $\left[{ }^{14} \mathrm{C}\right]$ aminoácidos, con estimulación del $75 \%$ de la actividad traduccional respecto al control. El análisis de los productos de traducción mostró un pico de incorporación correspondiente a péptidos con peso molecular aparente cercano al esperado (7,746 kDa). El OAs5, complementario a una secuencia de la estructura SLB del ARN-D2, inhibió completamente la traducción. Conclusiones. EI ARN-D2 fue traducido de manera específica y eficiente, bajo condiciones semejantes a las intracelulares en humanos, por un mecanismo alternativo independiente de la 5'cap, que involucraría a la estructura SLB. Este mecanismo podría considerarse como blanco en el desarrollo de terapias antisentido para inhibir la reproducción del virus.
\end{abstract}

Palabras clave: Virus del dengue; Biosíntesis de Proteínas; oligonucleótidos antisentido (fuente: DeCS BIREME)

\section{5'cap-INDEPENDENT TRANSLATION OF DENGUE VIRUS GENOMIC RNA}

\begin{abstract}
Objetives. To analyze the involvement of methyl guanosine triphosphate cap (5'cap) and the start site of the genomic RNA of Dengue virus serotype 2 (DENV-2) American genotype in translation, using a cell-free system prepared from human placenta. Materials and methods. The recombinant plasmid pTZ18R-D2 was prepared containing DNA encoding the 5'UTR and the first 201 nucleotides of the viral capsid. This plasmid was used to transcribe the corresponding RNA (RNA-D2) without the 5' cap. The RNA-D2 was translated in a system consisting of the postmitochondrial fraction (S-30) from human placenta and the incorporation of [14C] aminoacids in the presence of RNA-D2 and in its absence (control) was evaluated. Seven antisense oligonucleotides (OAs1-7) directed against sequences of the SLA, SLB and CHP structures of RNA-D2 were designed and the effect thereof on RNA-D2 translation was analyzed. Results. The RNA-D2 produced a significant increase $(p<0.001)$ in the incorporation of [14C] amino acids, with $75 \%$ stimulation of translational activity compared to the control. Analysis of the translation products showed peak incorporation corresponding to peptides with apparent molecular weight close to the expected $(7.746 \mathrm{kDa})$. The OAs5, complementary to a sequence of SLB structure of RNA-D2, completely inhibited translation. Conclusions. The RNA-D2 was translated specifically and efficiently under conditions similar to human intracellular conditions, by an alternative 5' cap-independent mechanism, which would involve the SLB structure. This mechanism might be seen as an aim in the development of antisense therapies to inhibit virus replication.
\end{abstract}

Key words: Dengue virus; Protein Biosynthesis; Oligonucleotides, Antisense (source: MeSH, NLM)

Facultad de Odontología. Universidad de Carabobo. Valencia, Venezuela.

2 Instituto de Investigaciones Biomédicas "Dr. Francisco J. Triana Alonso", Facultad de Ciencias de la Salud, Universidad de Carabobo. Sede Aragua, Maracay, Venezuela.

a Odontóloga, magíster en Ciencias Biomédicas; ${ }^{\circledR}$ licenciada en Bioanális; clicenciado en Bioanálisis, magíster en Ciencias Biomédicas; ${ }^{\circledR}$ licenciada en Bioanálisis; ${ }^{\mathrm{e}}$ licenciada en Biología, Magíster en Ciencias Biomédicas; ${ }^{\mathrm{f}}$ licenciada en Química, magíster en Ciencias Biomédicas; ${ }^{\mathrm{g}}$ licenciado en Química, doctor en Biología Molecular.

Recibido: 05-08-14 Aprobado: 11-02-15

Citar como: Pérez Dominguez M, Rojas R, Bandeira E, Requena D, Ferreras AC, Triana JL, et al. Traducción independiente de la estructura 5 'cap del ARN genómico del virus dengue. Rev Peru Med Exp Salud Publica. 2015;32(1):11-8. 


\section{INTRODUCCIÓN}

El virus del dengue (DENV) es un Flavivirus de la familia Flaviviridae y es agente causal de la enfermedad del dengue. El serotipo 2 (DENV-2) está relacionado con la infección más severa conocida como dengue hemorrágico ${ }^{(1)}$. El genoma del DENV consta de una cadena de ARN sentido positivo (ARN genómico) que actúa como ARN mensajero y, subsecuentemente, como molde para la replicación del virus. La secuencia traducible (ORF) del ARN genómico del DENV codifica una poliproteína única que es procesada en tres proteínas estructurales $(C, p r M$ y $E)$ y siete no estructurales (NS1, NS2A, NS2B, NS3, NS4A, NS4B y NS5). La ORF está flanqueada por las regiones no traducibles (UTR) 5'UTR y 3'UTR, que contienen estructuras secundarias conservadas (como las SLA y SLB, en la 5'UTR, y las SL, PK1 y PK2, en la 3'UTR) implicadas en la regulación de la traducción, replicación, transcripción y patogénesis viral ${ }^{(2-6)}$. El extremo de la 5'UTR presenta una estructura denominada caperuza 7-metil-guanosín-trifosfato (5'cap), propia de los ARNm eucariotas.

El mecanismo de traducción del ARN genómico del DENV, al igual que en eucariotas, depende del reconocimiento inicial y unión a la 5 'cap del factor elF4E y consecutivamente de los factores elF4A y elF4G. Este último interactúa con el complejo de preiniciación 43S, atrayéndolo hacia la 5 'cap. Seguidamente, este complejo se desplaza por la 5'UTR (proceso conocido como scanning) hasta encontrar el codón de iniciación AUG donde, luego de la unión de la subunidad 605 y formación del complejo traduccional 80S, comenzará la traducción del ARNm ${ }^{(7)}$. En este mecanismo también participa la cola de poli(A) del extremo 3'UTR a través de su proteína de unión PABP, la cual interactúa con el factor elF4G ubicado en la región 5'UTR, causando la formación de una estructura circular del ARNm que incrementa la eficiencia de la traducción ${ }^{(8)}$. Aunque el ARN genómico del DENV no posee cola de poli $(A)$, se ha demostrado que la PABP también puede unirse a su 3'UTR, por lo que posiblemente esta región tendría una participación semejante a la que tiene en la traducción del ARNm de eucariotas ${ }^{(9)}$.

El genoma de otros virus de la familia Flaviviridae (como Hepacivirus y Pestivirus) no posee la 5'cap, pero contiene elementos estructurados en la $5^{\prime}$ UTR que constituyen un sitio de entrada interna ribosomal (IRES). Estos IRES también se han identificado en miembros de las familias Picornaviridae, Retroviridae $y$ Herpesviridae y se caracterizan por inducir la formación del complejo traduccional cerca o directamente en el codón de iniciación AUG ${ }^{(10,11)}$. Aunque la presencia de la $5^{\prime}$ cap en el genoma del DENV supone un mecanismo de traducción dependiente de dicha estructura, se ha demostrado que en células BHK-21 C15 infectadas con DENV-2 y tratadas con LY294002 y Wortmannina (inhibidores de la traducción dependiente de $5^{\prime}$ cap) disminuye la síntesis de proteínas celulares, pero no de las virales ${ }^{(12)}$. Igualmente, se demostró que ARNm reporteros con las $5^{\prime}$ y $3^{\prime}$ UTRs del DENV-2, podían ser traducidos en extractos de células BHK-21 C15, aun en presencia de una 5 'cap no funcional o en condiciones que disminuían la disponibilidad de elF4E. Sin embargo, no se encontró una actividad de IRES que pudiese explicar la traducción independiente de 5 'cap del ARN genómico del DENV-2. En su lugar, se propuso un modelo en el cual la traducción en el DENV podía alternar entre el mecanismo canónico dependiente de la $5^{\prime}$ cap y otro independiente de dicha estructura. Este último dependería de la interacción de ambas UTRs a través algún factor aún no determinado (12). Dicha interacción induciría el ensamblaje del complejo traduccional en la $5^{\prime}$ UTR, evitando el requerimiento del elF4E y de la $5^{\prime}$ cap. Sin embargo, la exactitud de este modelo no está comprobada.

La existencia de un mecanismo alternativo de traducción en el DENV, independiente de la 5'cap, podría estar relacionada con el hecho de que el DENV no inhibe la traducción celular, pudiéndose reproducir en condiciones celulares adversas ${ }^{(3)}$, por tanto, podría servir como blanco terapéutico. Para profundizar más el conocimiento de dicho mecanismo, en el presente trabajo se obtuvo un fragmento del ARN genómico del DENV-2, conteniendo las secuencias de la $5^{\prime}$ UTR (sin la $5^{\prime}$ cap) y de los primeros 201 nucleótidos correspondientes a la cápside viral. Este ARN fue traducido en un sistema libre de células de placenta humana y se analizó el efecto sobre la traducción de oligonucleótidos antisentido (OAs), dirigidos contra diferentes secuencias de dicho ARN.

\section{MATERIALES Y MÉTODOS}

\section{OBTENCIÓN DEL PLÁSMIDO PARA TRANSCRIPCIÓN IN VITRO}

EI ADN que codifica los primeros 297 nucleotidos (nt) del genoma viral se amplificó a partir del plásmido p2(tonga/74) que contenía la secuencia completa del genotipo Americano del DENV-2(13) utilizando los cebadores 5'AGTAGTTAGTCTACGTGGACCG3' (directo) y 5'CTTCAATATCCCTGCTG TTG3' (reverso) y el producto de PCR (ADN-D2) fue purificado con el sistema Wizard ${ }^{\circledR}$ SV Gel and PCR Clean-Up System 
(Promega). EIADN-D2 se insertó en el sitio de restricción para EcoRI del plásmido pTZ18R (Pharmacia) mediante ligación por extremos romos generados con la enzima DNA polymerase I large (Klenow) fragment (Promega). El plásmido recombinante producto de la ligación (pTZ18R-D2) contenía la secuencia del ADN-D2 ubicada entre siete pares de bases $(\mathrm{pb})$ corriente abajo del promotor de la T7 polimerasa y cuatro $\mathrm{pb}$ al final de dicha secuencia, que regeneraban la diana para EcoRI en el pTZ18R. La regeneración de esta diana indicaba la ligación del ADN-D2 en la orientación correcta con respecto al promotor de la T7 ARN polimerasa. Luego de la ligación, la cepa XL1-blue de Escherichia coli fue transformada con el pTZ18R-D2 para su expansión y posterior purificación con el sistema Plasmid Midi Kit (QIAGEN). El pTZ18R-D2 purificado se verificó mediante restricción con Rsal (dianas en posiciones 456 del inserto y 2382 del pTZ18R), Bgll (dianas en posiciones 385 del inserto y 14 y 2022 del pTZ18R) y EcoRI (diana en la posición 328 del pTZ18). Los productos de restricción se analizaron mediante electroforesis en gel de agarosa (2\%).

\section{TRANSCRIPCIÓN IN VITRO DEL pTZ18R-D2}

El pTZ18R-D2 se linealizó con EcoRI y se utilizó en ensayos de transcripción in vitro bajo las condiciones descritas por Triana-Alonso et al. (14) utilizando $30 \mathrm{\mu g} /$ $\mathrm{mL}$ del pTZ18R-D2 y $600 \mathrm{U} / \mathrm{mL}$ de T7 ARN polimerasa (Promega). La mezcla de transcripción se incubó durante seis horas a $37^{\circ} \mathrm{C}$ y el transcrito obtenido (ARN-D2, sin la $5^{\prime}$ cap) se analizó mediante electroforesis en gel de agarosa (2\%). La cantidad de ARN-D2 en la mezcla de transcripción se cuantificó indirectamente mediante un método colorimétrico ${ }^{(15)}$ adaptado para determinar el fosfato liberado $(\mathrm{Pi})$ en la hidrólisis de nucleótidos en sistemas biológicos ${ }^{(16)}$, considerando la relación de moles $\mathrm{Pi}$ liberado por mol de nucleótido incorporado de 2/1, el número de nucleótidos del ARN-D2 y el peso molecular estimado para cada nucleótido. Se utilizó el programa Mfold www.bioinfo.rpi.edu/applications/ mfold/old/rna/) (17) para analizar la estructura secundaria probable del ARN-D2.

\section{HIBRIDACIÓN DE LOS OLIGONUCLEÓTIDOS ANTISENTIDO CON EL ARN-D2}

Se diseñaron siete oligonucleótidos antisentido (OAs) (Tabla 1). Cada OAs se incubó con la mezcla de transcripción a $70{ }^{\circ} \mathrm{C}$ por 5 min (relación molar del ARN-D2 contenido en la mezcla con respecto a cada OAs, de 1/5). La formación de híbridos (ARN-D2/OAs) se verificó mediante electroforesis en gel de agarosa $(2 \%)$ de la mezcla luego de incubar con cada OAs.
Tabla 1. Secuencias de los oligonucleótidos antisentido utilizados

\begin{tabular}{clc}
\hline Oligonucleótido & \multicolumn{1}{c}{ Secuencia } & nt \\
\hline AOs1 & 5'GTCTTTGTCCACGTAG 3' & $11-30$ \\
AOs2 & 5'CTTAGCTCCCT CAAAGAATCT 3' & $31-51$ \\
AOs3 & 5'CAAAAAACAGTTAGAACTACGTTGAG 3' & $52-77$ \\
AOs4 & 5'GCTCTCTAATCAAAAAACAG 3' & $68-87$ \\
AOs5 & 5'CATCAGAGATCTGCTC 3' & $84-99$ \\
AOs6 & 5'GTTTCTCGCCT TTTTCCGTTGG 3' & $105-126$ \\
AOs7 & 5'TTCAGCATATTGAAAGGCGT 3' & $127-146$ \\
\hline
\end{tabular}

\section{TRADUCCIÓN IN VITRO DEL ARN-D2}

La traducción del ARN-D2 se realizó en un sistema libre de células formado por la fracción posmitocondrial (S-30) de placenta humana. La obtención de esta fracción y las condiciones del ensayo de traducción para ARN mensajeros exógenos fueron descritas previamente ${ }^{(18)}$. Las mezclas de ensayo $(100 \mu \mathrm{L})$ contenían 0,28 unidades $A_{260}$ de la fracción S-30, 42 $\mu \mathrm{M}$ de $\left[{ }^{14} \mathrm{C}\right]$-aminoácidos (Amershan) $(608 \mathrm{dpm} / \mathrm{pmol})$ y volúmenes variables de la mezcla de transcripción conteniendo 1 a $5 \mu \mathrm{g}$ del ARN-D2. En algunos ensayos, la mezcla de transcripción fue incubada previamente con cada uno los OAs como se describió anteriormente. Los ensayos de traducción se incubaron a $37^{\circ} \mathrm{C}$ por $60 \mathrm{~min}$ y luego se procesaron para determinar la radiactividad (dpm) por contaje de centelleo líquido ${ }^{(18)}$. Los datos se analizaron con la prueba de múltiples comparaciones con el control de Dunnett, utilizando el software Statistix 8.0 para Windows.

Para analizar el producto de la traducción, se tomaron muestras de $25 \mu \mathrm{L}$ de las reacciones y se sometieron a electroforesis en gel de poliacrilamida-SDS (15\%). Al finalizar la electroforesis, los diferentes carriles del gel conteniendo las muestras se cortaron y dividieron en 16 segmentos de $0,5 \mathrm{~cm}$, se colocaron individualmente en viales con líquido de centelleo y se determinó la radiactividad asociada a cada segmento por contaje de centelleo líquido. Algunos carriles no fueron seccionados y se tiñeron con azul de Comassie.

\section{RESULTADOS}

TRASCRIPCIÓN IN VITRO DE LOS PRIMEROS 297 NUCLEÓTIDOS DEL GENOMA DEL DENV-2

EI ARN-D2 con los primeros $297 \mathrm{nt}$ del genoma del DENV2 se obtuvo mediante transcripción in vitro utilizando como molde el plásmido pTZ18R-D2, donde se insertó la secuencia del ADN-D2. La inserción correcta se verificó mediante análisis de restricción con Rsal, Bgll y EcoRI 


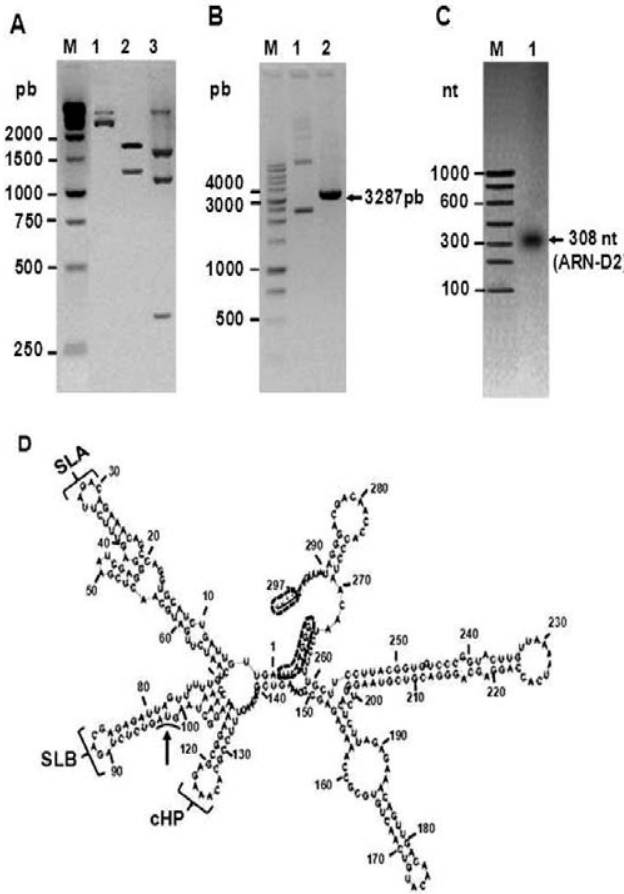

Figura 1. Análisis del pTZ18R-D2 y del ARN-D2. A). Separación en gel de agarosa al $2 \%$ del pTZ18R-D2 sin digerir (1) y digerido con Rsal (2) y Bgll (3) B). Separación en gel de agarosa al $0,8 \%$ del pTZ18R-D2 sin digerir (1) y digerido con EcoRI (2). M: marcador de ADN (pb). (C)transcripción in vitro del pTZ18R-D2. Al finalizar la incubación de la mezcla de transcripción, se tomaron $5 \mu \mathrm{L}$ (1) y se separaron en gel de agarosa al $2 \%$. M: marcador de ARN (nt). (D) estructura secundaria predicha para el ARN-D2 según el programa MFold. Se indican: 1) los nucleótidos en los extremos $5^{\prime}$ y $3^{\prime}$ del ARN-D2 (recuadros punteados) provenientes del pTZ18R, 2) el codón AUG de inicio de la traducción (flecha) y 3) las estructuras secundarias SLA, SLB y cHP del genoma viral.

(Figura 1). El tratamiento con $R$ sal rindió los dos fragmentos esperados de 1926 y $1361 \mathrm{pb}$, mientras que Bgll produjo los tres fragmentos esperados de 371, 1637 y $1279 \mathrm{pb}$ (Figura 1A). Por otra parte, EcoRI (cuya diana se regenera en el pTZ18R únicamente si el ADN-2 se insertó en la orientación correcta) originó el plásmido lineal esperado de $3287 \mathrm{pb}$ (Figura 1B). Esto demuestra que el pTZ18R-D2 contiene la secuencia del ADN-D2 adyacente al promotor para la $T 7$ polimerasa y en la orientación indicada para que la transcripción rinda el ARN-D2 con los primeros $297 \mathrm{nt}$ del DENV-2, los cuales estarán flanqueados en los extremos $5^{\prime}$ y $3^{\prime}$ terminales por siete y cuatro $\mathrm{nt}$, respectivamente, pertenecientes al pTZ18R.

La síntesis del ARN-D2 se corroboró mediante electroforesis en gel de agarosa de la mezcla de transcripción al observar que el producto fue una banda única, con el tamaño esperado de 308 nt (Figura 1C). La predicción de la estructura secundaria más probable para la secuencia de nucleótidos del ARN-D2 obtenido, mostró que se preservan las estructuras SLA, SLB y cHP, implicadas en la replicación y traducción del genoma del DENV ${ }^{(3,4)}$ (Figura 1D).

\section{TRADUCCIÓN DEL ARN-D2 EN EL SISTEMA LIBRE DE CÉLULAS DE PLACENTA HUMANA Y EFECTO DE LOS OLIGONUCLEÓTIDOS ANTISENTIDO SOBRE LA TRADUCCIÓN}

La traducción del ARN-D2 se realizó en un sistema libre de células constituido por la fracción S-30 de placenta humana (la cual contiene toda la maquinaria traduccional: factores, ARNt y polisomas) ${ }^{(18)}$ utilizando la mezcla de transcripción in vitro con diferentes cantidades estimadas del transcripto ARN-D2 (Figura 2). La presencia del ARN-D2 en el ensayo de traducción produjo un incremento significativo $(p<0,001)$ en la incorporación de $\left[{ }^{14} \mathrm{C}\right]$-aminoácidos (entre 1300 y 1630
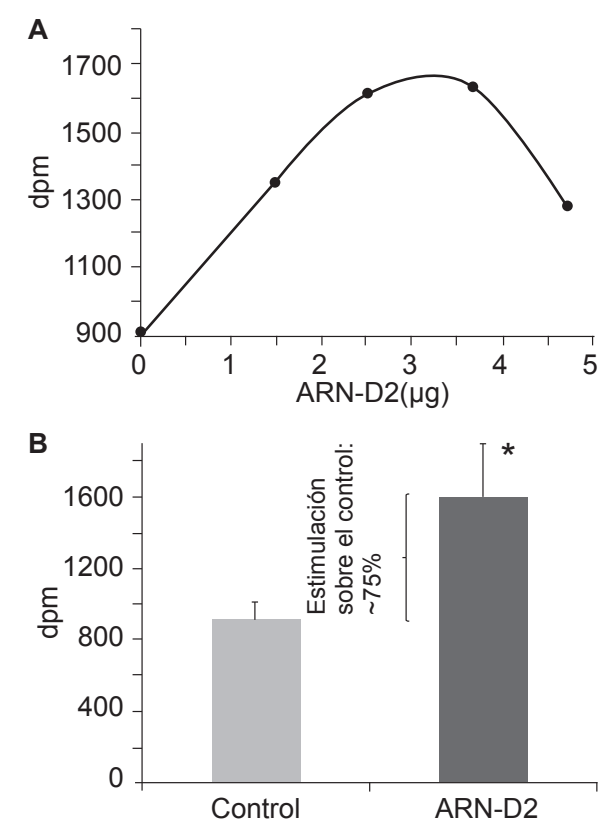

Figura 2. Traducción del ARN-D2 en el sistema libre de células de placenta humana. A) Cantidades crecientes del ARN-D2, contenido en la mezcla de transcripción, fueron incubadas con la fracción S-30 de placenta humana en un volumen final de $100 \mu \mathrm{L}$, bajo condiciones de ensayo para traducción in vitro previamente optimizadas ${ }^{(18)}$. B) Comparación de la actividad traduccional en ausencia (control) y en presencia $2,5 \mu \mathrm{g}$ del ARN-D2. Se indica el porcentaje estimado de estimulación de la incorporación. Se representan los promedios de cuatro ensayos con sus respectivas desviaciones estándar. $\left(^{*}\right)$ Significativamente diferente del control $(p<0,001)$. La radiactividad (dpm) corresponde a $\left[{ }^{14} \mathrm{C}\right]$ aminoácidos incorporados en polipéptidos sintetizados. 
A
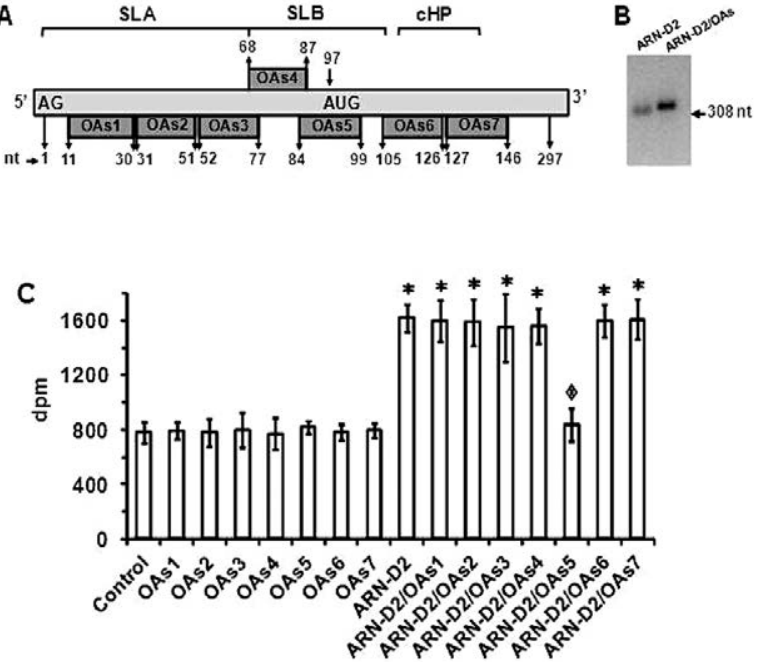

Figura 3. Efecto de los OAs sobre la traducción del ARN-D2. A) Mapa de hibridación de cada uno de los OAs con sus secuencias complementarias en el ARN-D2. Se indican las posiciones del rango de nucleótidos (nt) que abarca cada OAs y las estructuras SLA, SLB y cHP. B) Análisis electroforético en gel de agarosa (2\%) del ARN-D2 antes y después de incubar con los OAs (ARN-D2/OAs). Se muestra el patrón típico obtenido para todos los OAs. C) Incorporación de $\left[{ }^{14} \mathrm{C}\right]$ aminoácidos (dpm) en el sistema de traducción de placenta humana en ausencia del ARN-D2 (Control) y en presencia de: 1) cada uno de los OAs (OAs1-7), 2) la mezcla de transcripción (ARN-D2) y 3) la mezcla de transcripción incubada con cada uno de los OAs (ARN-D2/OAs1-7). Promedio de cuatro ensayos con la desviación estándar. $\left(^{*}\right)$ Significativamente diferente $(p<0,001)$ respecto a la incorporación en presencia de cada OAs1-7. (1) Significativamente diferente $(p<0,001)$ respecto a la incorporación en presencia del ARN-D2.

dpm) en comparación con el ensayo control sin adición del ARN-D2 (900 dpm) (Figura 2A). La incorporación observada en el control corresponde a la traducción del ARNm endógeno presente en la fracción S-30. La máxima incorporación se obtuvo en presencia de 2,5$3,7 \mu \mathrm{g}$ de ARN-D2, estimándose un $75 \%$ de estimulación respecto al control en presencia de $2,5 \mu \mathrm{g}$ de ARN-D2 (Figura 2B). Estos resultados demuestran la traducción independiente de 5'cap del ARN-D2, en el sistema utilizado.

Para determinar secuencias en el ARN-D2 involucradas en la traducción, los ensayos se realizaron en presencia de OAs (añadidos como híbridos ARN-D2/ OAs) (Figura 3). Los OAs diseñados (Tabla 1) eran complementarios a secuencias entre las posiciones 11 y 146 del ARN-D2 donde se ubicarían las estructuras SLA, SLB y cHP (Figura 3A). La formación de híbridos ARN-D2/OAs se comprobó por el retardo en el patrón de migración electroforética del ARN-D2 luego de incubarlo con cada OAs (Figura 3B, muestra el patrón típico). Cuando se añadió el híbrido ARN-D2/OAs5 al ensayo de traducción, hubo una disminución significativa $(p<0,001)$ de la incorporación de ${ }^{14}[\mathrm{C}]$-aminoácidos en relación a cuando se añadió el ARN-D2 solo (Figura 3C). El resto de los híbridos no tuvieron efecto significativo $(p>0,05)$ sobre la incorporación y ninguno de los OAs por sí solos afectaron la traducción del ARNm endógeno del sistema (control). Por tanto, el efecto inhibitorio del OAs5 fue específico para la traducción del ARN-D2.

Para determinar si el ARN-D2 codifica el polipéptido esperado (región inicial de la cápside de 7,746 kDa), se analizaron los productos de traducción. Para ello, muestras de la reacción se sometieron a electroforesis en gel de poliacrilamida-SDS y los carriles del gel se seccionaron y procesaron como se indicó en materiales y métodos (Figura 4). Al determinar la radiactividad asociada a los segmentos del gel, se detectó un pico en el patrón de separación de la mezcla del ensayo conteniendo el ARN-D2, que no es detectable en los ensayos sin ARN-D2 (control) o en presencia del híbrido ARN-D2/OAs5. Este pico pertenece al segmento 13, correspondiente a polipéptidos en el rango de 5,8$7,5 \mathrm{kDa}$, donde se ubicaría muy cercanamente el

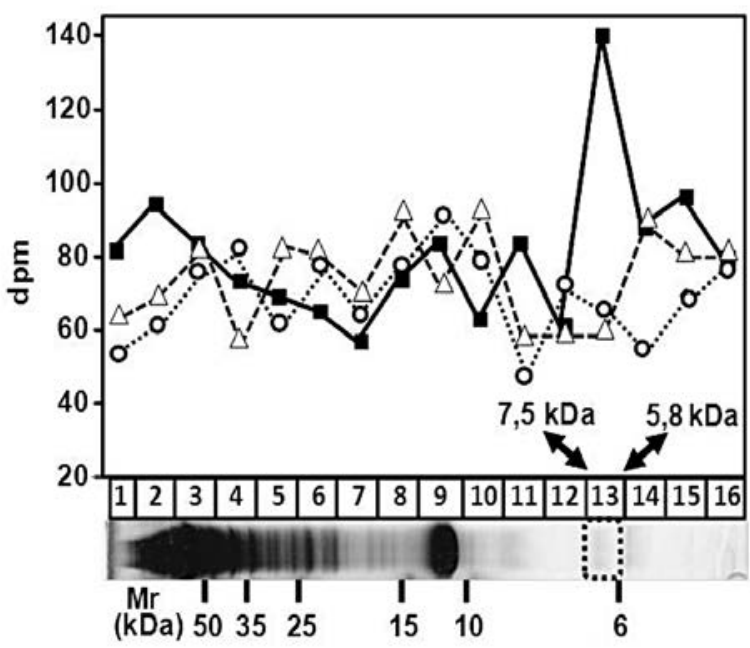

Figura 4. Análisis del producto de la traducción de ARN-D2. Muestras de los ensayos de traducción in vitro realizados en ausencia $(\Delta)$ y en presencia del ARN-D2 solo ( $\square$ ) o en forma de híbrido ARN-D2/OAs5 (o), fueron separadas mediante electroforesis en gel de poliacrilamida-SDS (15\%). Los carriles del gel se seccionaron en 16 fragmentos $(1 \rightarrow 16)$ y se determinó la radioactividad (dpm) asociada a cada uno. Se muestra uno de los carriles del gel sin seccionar y teñido con azul de Coomassie y patrón de pesos moleculares $(\mathrm{kDa})$ utilizado. Las flechas indican el rango estimado de pesos moleculares para los péptidos contenidos en la fracción $\mathrm{N} .^{\circ} 13$. 
polipéptido esperado de 7,746 kDa. Esto corrobora que la radiactividad extra detectada en los ensayos donde está presente el ARN-D2, se debe principalmente a la síntesis del polipéptido codificado por este y que la inhibición producida por el OAs5 es específica para dicha síntesis. En los carriles no seccionados y teñidos con azul de Comassie, se observaron, principalmente, los polipéptidos contenidos en la fracción S-30 de placenta humana, con el perfil de separación esperado para este tipo de extracto celular ${ }^{(18)}$.

\section{DISCUSIÓN}

Los resultados obtenidos indican que el ARN-D2 con los primeros $297 \mathrm{nt}$ del genoma del DENV-2 y sin la estructura $5^{\prime}$ cap, puede ser traducido por los ribosomas de placenta humana y sintetizar un polipéptido del tamaño esperado. Esto constituye el primer reporte de traducción in vitro de la secuencia inicial del genoma del DENV-2, de manera independiente de la 5'cap en un sistema libre de células de origen humano. El polipéptido principal sintetizado presentó un peso molecular cercano al esperado, por lo que la traducción debió comenzar en el primer codón AUG que se encuentra en la región SLB de la $5^{\prime}$ UTR del genoma viral (Figura 1C). Esto indica que en la traducción del ARN-D2 en el sistema utilizado se deben mantener los mismos mecanismos dependientes de las secuencias y estructuras del ARN genómico viral, que permiten in vivo la iniciación de la traducción en el AUG correcto.

La traducción del ARN-D2 resultó eficiente, especialmente si se considera que no contiene la $5^{\prime}$ cap y que compite por los ribosomas con el ARNm endógeno presente en la fracción S-30 de placenta humana, lo cual teóricamente representaría una desventaja. Sin embargo, un incremento en la incorporación del $75 \%$ sobre el ARNm endógeno por efecto del ARN-D2 (Figura 2B) que codifica un péptido muy pequeño, indica la síntesis de varias copias del mismo. Esto refleja una relativa estabilidad del ARN-D2 y una alta eficiencia en interactuar con la maquinaria traduccional, a pesar de no poseer la 5'cap.

La presencia de la 5'cap en el genoma del DENV supone el mecanismo de iniciación de la traducción dependiente de esta estructura, al igual que en los ARNm de eucariotas. Sin embargo, se ha propuesto la hipótesis de que la iniciación de la traducción en DENV2 puede alternar entre el mecanismo dependiente de 5 'cap y otro independiente. Este último no involucraría un IRES, sino la interacción de los extremos de ambas UTRs, lo cual favorecería la unión a la 5 'UTR de los factores elF4G y elFA, evitando el requerimiento del elF4E (12). Sin embargo, no se ha determinado las estructuras o proteínas involucradas en dicha interacción. En la replicación del DENV y otros Flavivirus se ha demostrado una interacción entre las UTRs que implica secuencias conservadas en las 5'UTR y $3^{\prime}$ UTR que promueven la circularización del genoma viral, la cual parece ser fundamental para la síntesis del ARN, pero no para su traducción ${ }^{(19)}$.

La participación de la 3'UTR en la traducción del genoma del DENV dependiente de 5 'cap, no está completamente aclarada. Sin embargo, los resultados obtenidos en estudios con células BHK-21 C15 transfectadas con ARNm reporteros donde se suprimieron dominios conservados de la $3^{\prime}$ UTR ${ }^{(20)}$ y en replicones virales con supresión completa de la $3^{\prime}$ UTR (19), además de la demostración de que la PABP interactúa con la 3 'UTR del DENV-2 ${ }^{(9)}$, sugieren que esta región tiene una función moduladora de la traducción en el DENV, aunque no determinante de la misma. Los resultados obtenidos en el presente trabajo indican que no se requiere de la interacción de las UTRs para la traducción independiente de 5'cap del ARN-D2, ya que este no contenía la 3'UTR. Esto constituye un aspecto novedoso que demuestra que la iniciación independiente de 5 'cap en DENV-2 puede ser dirigida únicamente por la $5{ }^{\prime}$ UTR, por algún mecanismo de entrada interna no descrito aún en Flavivirus.

El efecto de los OAs diseñados arrojó datos interesantes para entender el mecanismo de traducción del ARN-D2. El OAs5 dirigido contra parte de la secuencia de la SLB, incluyendo el codón de iniciación AUG, inhibió casi completamente la traducción del ARN-D2, mientras que los otros OAs dirigidos contra secuencias en la SLA y la cHP no tuvieron efectos significativos (Figura 3C). Aparentemente, la presencia del OAs5 bloqueó la unión del ribosoma y/o la interacción de factores traduccionales con esa secuencia particular en el ARN-D2. Los resultados obtenidos sugieren que la maquinaria traduccional parece interactuar directamente con la secuencia comprendida entre las posiciones 84 y 99 del ARN-D2 y que esta podría constituir o formar parte de un IRES, que incluiría al codón de iniciación AUG. Este tipo de IRES existe en el genoma de otros virus de la familia Flaviviridae, como el de la hepatitis C (HCV) y el de la fiebre porcina clásica (CSFV), y se caracteriza por contener elementos que abarcan desde $5^{\prime}$ UTR hasta la región codificante, donde se unen muy cercanamente al codón AUG la subunidad 40S, el elF3 y el complejo ternario, omitiendo la necesidad de los factores elF4E, elF4G y elF4A, y el proceso de scanning ${ }^{(21,22)}$. 
El hecho de que los OAs dirigidos contra secuencias en la SLA y en la cHP no tuviesen efecto inhibitorio, sugiere que las mismas no participan en el mecanismo de entrada interna para la traducción del ARN-D2. El caso de la cHP resulta interesante pues se encuentra en la región codificante (14 nucleótidos corriente abajo del AUG de inicio) y se ha identificado como un elemento que estimula la selección del AUG correcto durante la iniciación de la traducción dependiente de $5^{\prime}$ cap en el DENV-2 ${ }^{(23,24)}$. Esta estructura ofrece un impedimento estérico al avance del complejo $43 S$ durante el proceso de scanning, lo cual induciría una pausa sobre el codón de iniciación AUG, facilitando la formación del complejo de iniciación $80 \mathrm{~S}$ en este codón. Asumiendo la hipótesis de que en la iniciación de la traducción del ARN-D2 la entrada interna sería en la región donde se encuentra el AUG, la función de la cHP como facilitadora en la selección de este codón, no sería necesaria. Por otra parte, aparentemente la hibridación de un OAs en esta región codificante parece no afectar la traducción, probablemente el avance del complejo ribosomal tiene la capacidad de desestabilizar las interacciones ARNARN que se presentan en dicha región.

Estudios previos han fallado en demostrar la existencia de un IRES en el genoma del DENV2 ${ }^{(12)}$. Es posible que los constructos de ARNm reporteros bicistrónicos diseñados para estos estudios (donde la 5'UTR del DENV se insertó entre las secuencias de un IRES no funcional del virus de la encefalomiocarditis y de la proteína luciferasa) no eran apropiados para detectar la presencia de un IRES funcional. Por ejemplo, se ha señalado que la detección eficiente de IRES en los genomas del HCV y del CSFC, depende en gran medida de la secuencia codificante de la proteína reportera escogida para fusionar con la $5^{\prime}$ UTR del genoma viral y de la inclusión de secuencias de la región codificante próximas al codón $A \cup G{ }^{(25,26)}$. Esto indica la influencia de las regiones aledañas al codón de iniciación AUG en la funcionalidad de los IRES que incluyen este codón en su estructura.
El ARN-D2 obtenido y utilizado en el presente estudio resulta más conveniente que los constructos de ARNm reporteros virales para estudiar el mecanismo de iniciación independiente de 5'cap en DENV, pues contiene la secuencia original de los primeros $297 \mathrm{nt}$ del genoma del DENV-2, donde se deben conservar las estructuras secundarias de la $5^{\prime}$ UTR y de parte de la región codificante de la cápside. Aunque se requieren más estudios para establecer que la secuencia comprendida entre las posiciones 84-99 de la estructura SLB constituye un IRES en el genoma viral, los resultados obtenidos en el presente estudio soportan esa hipótesis.

Finalmente, la traducción del ARN-D2 en un sistema de origen humano resulta muy apropiada para el estudio de los mecanismos moleculares de la síntesis de proteínas virales, ya que representaría un contexto similar al citoplasma del humano al cual se enfrenta el virus durante su ciclo de vida. Por otra parte, la utilización de oligonucleótidos antisentido en este sistema constituye una herramienta de gran utilidad para comprender los mecanismos reguladores de la síntesis de proteínas virales y para el desarrollo de alternativas terapéuticas dirigidas a bloquear la traducción del genoma viral y, en consecuencia, su ciclo de vida en el hospedador humano.

Agradecimientos: al Dr. Tadeusz J. Kochel (Naval Medical Research Center, Silver Spring, Maryland, USA) por donar el plásmido que contiene el genoma completo del virus dengue serotipo 2, genotipo Americano.

Contribuciones de autoría: MPD, RR, EB y DR participaron en la recolección y obtención de resultados. Además, MPD participó en el análisis e interpretación de los datos. ACF y JLT participaron en el análisis e interpretación de los datos y en la redacción, revisión y aprobación final del artículo. FTA en vida, participó en la concepción, diseño, desarrollo y en el análisis de datos del trabajo presentado.

Fuentes de financiamiento: Consejo de Desarrollo Científico y Humanístico (CDCH) de la Universidad de Carabobo.

Conflictos de interés: los autores declaran no tener conflictos de interés

\section{REFERENCIAS BIBLIOGRÁFICAS}

1. Lindenbach B, Thiel H, Rice C. Flavivirus. The virus and their replication. En: Knipe D, Howley Peter. Fields Virology. Philadelphia: Lippincott Williams \& Wilkins; 2007. p. 1101-52.

2. Wei Y, Qin C, Jiang T, Li X, Zhao H, Liu Z, et al. Translational regulation by the 3 ' untranslated region of the dengue type 2 virus genome. Am J Trop
Med Hyg. 2009 Nov;81(5):817-24. doi: 10.4269/ajtmh.2009.08-0595.

3. Paranjape SM, Harris E. Control of dengue virus translation and replication. Curr Top Microbiol Immunol. 2010;338:15-34. doi: 10.1007/978-3-642-02215-9_2.

4. Gebhard LG, Filomatori CV, Gamarnik AV. Functional RNA elements in the dengue virus genome. Viruses. 2011
Sep;3(9):1739-56. doi: 10.3390/ v3091739.

5. Manzano M, Reichert ED, Polo $S$, Falgout B, Kasprzak W, Shapiro BA, et al. Identification of cis-acting elements in the 3'-untranslated region of the dengue virus type 2 RNA that modulate translation and replication. J Biol Chem. 2011 Jun 24;286(25):2252134. doi: 10.1074/jbc.M111.234302. 
6. Sztuba-Solinska J, Teramoto T, Rausch JW, Shapiro BA, Padmanabhan R, Le Grice SF. Structural complexity of Dengue virus untranslated regions: cisacting RNA motifs and pseudoknot interactions modulating functionality of the viral genome. Nucleic Acids Res. 2013 May;41(9):5075-89. doi: $10.1093 / \mathrm{nar} / \mathrm{gkt} 203$.

7. Sonenberg N, Hinnebusch AG. Regulation of translation initiation in eukaryotes mechanisms and biological targets. Cell. 2009 Feb 20;136(4):73145. doi: 10.1016/j.cell.2009.01.042.

8. Jackson RJ, Hellen CU, Pestova TV. The mechanism of eukaryotic translation initiation and principles of its regulation. Nat Rev Mol Cell Biol. 2010 Feb;11(2):113-27. doi: 10.1038/ nrm2838.

9. Polacek C, Friebe P, Harris E. Poly(A)-binding protein binds to the non-polyadenylated 3' untranslated region of dengue virus and modulates translation efficiency. J Gen Virol. 2009 Mar;90(Pt 3):687-92. doi: 10.1099/ vir.0.007021-0.

10. Pestova TV, Kolupaeva VG, Lomakin IB, Pilipenko EV, Shatsky IN, Agol VI, et al. Molecular mechanisms of translation initiation in eukaryotes. Proc Natl Acad Sci U S A. 2001 Jun 19;98(13):7029-36.

11. Martínez-Salas E, Piñeiro D, Fernández N. Alternative Mechanisms to Initiate Translation in Eukaryotic mRNAs. Comp Funct Genomics. 2012;2012:391546. doi: 10.1155/2012/391546.

12. Edgil D, Polacek C, Harris E. Dengue virus utilizes a novel strategy for translation initiation when capdependent translation is inhibited. J Virol. 2006 Mar;80(6):2976-86.

13. Blaney JE Jr, Hanson CT, Hanley KA, Murphy BR, Whitehead SS. Vaccine candidates derived from a novel infectious cDNA clone of an American genotype dengue virus type 2. BMC Infect Dis. 2004 Oct 4;4:39.

14. Triana-Alonso FJ, Dabrowski M, Wadzack J, Nierhaus KH. Self-coded 3'-extension of run-off transcripts produces aberrant products during in vitro transcription with T7 RNA polymerase. J Biol Chem. 1995 Mar 17;270(11):6298-307.

15. González-Romo P, Sánchez-Nieto $S$, Gavilanes-Ruíz M. A modified colorimetric method for the determination of orthophosphate in the presence of high ATP concentrations. Anal Biochem. 1992 Feb 1;200(2):235-8.

16. Bandeira E, Ferreras AC, Bacilio D, Galvis G, Parada H, Cayama E, et al. Actividad ATP hidrolasa asociada a ribosomas humanos como nuevo indicador para evaluar fármacos in vitro. Salus. 2007;11(3):46-50.

17. Zuker M. Mfold web server for nucleic acid folding and hybridization prediction. Nucleic Acids Res. 2003 Jul; 31(13):3406-15.

18. Ferreras AC, Bandeira E, Cayama E, Zambrano R, Avila H, Yépez A, et al. Efficient and faithful in vitro translation of natural and synthetic mRNA with human ribosomes. Int J Mol Med. 2004 Apr;13(4):527-36.

19. Alvarez DE, De Lella Ezcurra AL, Fucito S, Gamarnik AV. Role of RNA structures present at the 3'UTR of dengue virus on translation, RNA synthesis, and viral replication. Virology. 2005 Sep 1;339(2):200-12.

20. Chiu WW, Kinney RM, Dreher TW. Control of translation by the 5'- and 3'-terminal regions of the dengue virus genome. J Virol. 2005 Jul;79(13):8303-15.

21. Pestova TV, Shatsky IN, Fletcher SP, Jackson RJ, Hellen CU. A prokaryoticlike mode of cytoplasmic eukaryotic ribosome binding to the initiation codon during internal translation initiation of hepatitis $\mathrm{C}$ and classical swine fever virus RNAs. Genes Dev. 1998 Jan 1;12(1):67-83.

22. Lukavsky PJ. Structure and function of HCV IRES domains. Virus Res. 2009 Feb;139(2):166-71. doi: 10.1016/j. virusres.2008.06.004.

23. Clyde K, Harris E. RNA secondary structure in the coding region of dengue virus type 2 directs translation start codon selection and is required for viral replication. J Virol. 2006 Mar;80(5):2170-82.

24. Clyde K, Barrera J, Harris E. The capsidcoding region hairpin element $(\mathrm{cHP})$ is a critical determinant of dengue virus and West Nile virus RNA synthesis. Virology. 2008 Sep 30;379(2):314-23. doi: 10.1016/j.virol.2008.06.034.

25. Rijnbrand R, Bredenbeek PJ, Haasnoot PC, Kieft JS, Spaan WJ, Lemon SM The influence of downstream protein-coding sequence on internal ribosome entry on hepatitis $\mathrm{C}$ virus and other flavivirus RNAs. RNA. 2001 Apr;7(4):585-97.

26. Fletcher SP, Jackson RJ. Pestivirus internal ribosome entry site (IRES) structure and function: elements in the 5' untranslated region important for IRES function. J Virol. 2002 May;76(10):5024-33.

Correspondencia: Ana Celia Ferreras Casado

Teléfono: +58-243-2425822

Dirección: Instituto de Investigaciones Biomédicas "Dr. Francisco J. Triana Alonso" (BIOMED), calle Cecilio Acosta, Urb. La Rinconada, Las Delicias, Maracay, estado Aragua, Venezuela.

Correo electrónico: anaceliaf@hotmail.com 